\title{
A ESTRATÉGIA DE (RE)CATEGORIZAÇÃO NA INTERFACE ENTRE POLIDEZ E IMPOLIDEZ LINGUÍSTICA
}

(The strategyof (re)categorization as an interface between linguistic politeness and impoliteness)

\author{
Geórgia Maria Feitosa e Paiva ${ }^{1}$ \\ Universidade da Integração Internacional da Lusofonia Afro-Brasileira
}

Francisca Poliane Lima de Oliveira ${ }^{2}$

Secretaria de Educação de Horizonte

\section{RESUMO}

A partir do entendimento de que a comunicação se estabelece para manter as relações sociais e não apenas informar algo, muitos linguistas passaram a se preocupar em estudar as questões de polidez e impolidez ligadas a essas manifestações sociais de comunicação. Nesse sentido, nossa investigação teve como objetivo compreender o processo de recategorização como instrumento de interface entre a polidez e a impolidez linguística, a partir da análise da ação de comunicação interna promovida pela empresa Coca-Cola para a comemoração do dia Internacional do Orgulho LGBT no ano de 2017. Para realizar esta pesquisa, buscamos fazer um estudo de caso a partir da campanha "Essa Coca-Cola é fanta. E dai??". Adotamos, como norte para esta pesquisa, os estudos de Leech (1983) e de Brown e Levinson (1987), na área da polidez; de Butler (1990, 1993),na área de gênero; e de Apothéloz e Reichler-Béguelin (1995) e de Jaguaribe (2007), na área da recategorização. A partir do exposto, observamos que o processo de recategorização ocorreu em duas situações: a primeira se deu no plano material a partir da retomada discursiva de uma expressão idiomática tipicamente ofensiva contra o grupo LGBT e da inserção de uma nova expressão; e a segunda se deu no plano social com a sugestão de mudança no sentido da expressão e na postura das pessoas. Desse modo, concluímos que o processo de recategorização não pôde ser visto, neste exemplar, como apenas um processo de retomada do referente e de sua transformação, uma vez que, na campanha da marca de refrigerante em apreço, percebemos que tal processo foi ainda capaz de gerar uma alteração social (além da embalagem da latinha), demonstrando, assim, outro nível de recategorização, a partir da transformação de uma expressão tipicamente impolida em polida.

Palavras-Chave: Recategorização. Interdiscurso. Polidez. Impolidez. Coca-Cola.

\begin{abstract}
From the understanding that communication is established to maintain social relations and not just to inform something, many linguists have become concerned with studying the issues of politeness and impoliteness as sociated with these social manifestations of communication. In this sense, ou rresearch aimed to understand the recategorization process as na instrument of interface between polite and impolite language. From the analysis of the internal communication action promoted by the Coca-Cola company to celebrate the International LGBT Pride Day in 2017. To conduct this research, we sought to make a case study about the campaign "This Coca-Cola is Fanta. Sowhat?". Based on the studies in the área of politeness by Leech
\end{abstract}

\footnotetext{
${ }^{1}$ Doutora e mestre em Linguística (2013) pela Universidade Federal do Ceará. Professora Adjunto A da Universidade da Integração Internacional da Lusofonia Afro-Brasileira, editora-chefe da Revista de Estudos Linguísticos Mandinga. Líder do grupo de pesquisa Grupo de Estudos em Preconceito, Polidez e Impolidez Linguística (GEPPIL), tendo trabalhos apresentados e publicados em periódicos e livros nas áreas de polidez, impolidez, comunicação e educação. E-mail: georgiafeitosa@unilab.edu.br

${ }^{2}$ Doutora e mestre em Linguística Aplicada (2017) pela Universidade Estadual do Ceará, participante do grupo de pesquisa G.E.E.N.T.E. Tendo trabalhos apresentados e publicados em periódicos e livro nas áreas de ensino, linguística de texto, referenciação, semiótica e design. Atuou como consultora e formadora de professores pelo programa do governo do estado MAIS PAIC. E-mail: meuemail.poly@gmail.com
} 
(1983), Brown and Levinson (1987), and the área of gender with Butler (1990, 1993) and, in the area of recategorization, with Apothéloz and Reichler-Béguelin(1995) and Jaguaribe (2007), we observed that the process of recategorization occurred in two situations: the first was in the material level from the discursive resumption of a typically offensive idiom against the LGBT group and the insertion of a new expression; The second was on the social level with the suggestion of a change in the people's expression and attitude. Thus, we conclude that the recategorization process could not be seen, in this issue, as just a process of retaking the referent and its transformation, since, in the campaign of the soft drink brand under consideration, we realized that this process was still capable of generating a social change (beyond the pack aging of the can), thus demonstrating another level of recategorization, that is, the ability to transform a typically na impolite expression into a polite one.

Keywords: Recategorization. Interdiscourse. Politeness. Impoliteness. Coca-Cola.

\section{RESUMEN}

Desde el entendimiento de que la comunicación se establece para mantener las relaciones sociales y no solo para informar algo, muchos lingüistas comenzaron a preocuparse por estudiar los problemas de cortesía y descortesía asociados con esas manifestaciones sociales de la comunicación. En ese sentido, nuestra investigación tuvo como objetivo comprender el proceso de recategorización como un instrumento de interfaz entre la cortesía y la descortesía lingüística, a partir del análisis de la acción de comunicación interna promovida por la compañía Coca-Cola para conmemorar el Día Internacional del Orgullo LGBT en 2017. Para llevar a cabo esta investigación, buscamos hacer un estudio de caso de la campaña "Essa CocaCola é Fanta. E dai??" Adoptamos, como norte para esta investigación, los estudios de Leech (1983) y Brown y Levinson (1987) en el área de la cortesía; Butler (1990, 1993), en el área del género; y Apothéloz y Reichler-Béguelin (1995) y Jaguaribe (2007), en el área de la recategorización. De lo anterior, observamos que el proceso de recategorización se dió en dos situaciones: la primera ocurrió en el plano material a partir de la reanudación discursiva de un modismo típicamente ofensivo contra el grupo LGBT y de la inserción de una nueva expresión; y la segunda situación ocurrió a nivel social con la sugerencia de cambio del sentido del modismo y de la postura de las personas. Por lo tanto, concluimos que el proceso de recategorización no puede verse, en este caso, como un simple proceso de retomar el referente y su transformación, ya que, en la campaña de la marca de refrescos en consideración, nos dimos cuenta de que ese proceso todavía fue capaz de generar un cambio social (más allá del empaque de la lata), demostrando, así, otro nivel de recategorización a partir de la transformación de una expresión típicamente descortés en cortés.

Palabras clave: Recategorización. Interdiscurso. Cortesía. Descortesía; Coca-Cola.

Recebido em: dezembro 2019

Aceito em: dezembro 2019

DOI: $\underline{10.26512 / l e s . v 20 i 3.28635}$

\section{INTRODUÇÃO}

A linguagem é provavelmente a marca mais notória da cultura. As trocas simbólicas permitem a comunicação, geram relações sociais e mantêm ou interrompem essas relações. Por reconhecermos o valor e a complexidade de tais relações, neste artigo almejamos, como objetivo geral, compreender o processo de recategorização sob a perspectiva de uma interface entre a polidez e a impolidez linguística. Para isso, recorremos a um corpus gerado a partir da ação de comunicação interna promovida pela empresa Coca-Cola em comemoração ao dia Internacional do Orgulho 
LGBT no ano de 2017. Articulado a esse objetivo geral, elencamos os seguintes objetivos específicos: (a) apresentar a relação contínua entre polidez e impolidez linguística a partir do corpus analisado; e (b) demonstrar que essa relação pode se dar a partir de técnicas de recategorização.

Como quadro teórico, buscamos relacionar três áreas distintas a partir do pressuposto de que a recategorização é uma atividade que ocorre na/e além da materialidade textual. Para isso, buscamos estabelecer uma interseção entre os estudos depolidez e impolidez linguística, de recategorização e de gênero. Com relação a (im)polidez linguística, amparamo-nos nos estudos desenvolvidos por Leech (1983), Brown e Levinson (1987) e Culpeper (1996). No campo da recategorização, baseamo-nos em Apothéloz e Reichler-Béguelin(1995),Apothéloz (2001), Ciulla (2008),Jaguaribe (2007) e Oliveira (2017). No que se refere aos estudos de gênero, consideramos os pressupostos defendidos por Butler (1990; 1993), permitindo-nos compreender a construção do gênero também como processo de recategorização imaterial e simbólico.

Desse modo, o presente estudo apresenta, além desta introdução e das considerações finais, quatro itens. Os dois primeiros trazem reflexões teóricas nos campos da polidez e impolidez, e da recategorização; o terceiro discorre sobre a metodologia empregada nesse trabalho de pesquisa; e o último apresenta o resultado de nossas análises em relação aos dados coletados.

\section{POLIDEZ E IMPOLIDEZ LINGUÍSTICA: UM DIÁLOGO POSSÍVEL}

No final da década de setenta, depois da popularização do princípio de cooperação de Grice (1982), muitos linguistas consagrados buscaram compreender a linguagem muito além das máximas conversacionais. Neste cenário, surgiram as propostas de Lakoff (1973), Leech (1983), e Brown e Levinson (1987), que visaram, antes de tudo, a demonstrar que muito do que é comunicado se baseava mais na expectativa de estabelecer/manter uma relação social, mesmo que imediata, do que propriamente manter um contrato conversacional com vistas à comunicação de uma informação.

Isto sugere que a interação em si tem um peso muito mais relevante do que a qualidade e a quantidade de informação, por exemplo, e que o autêntico contrato conversacional é permeado por normas que regem a maneira pela qual são emitidas e recebidas as informações, de modo que satisfaçam, em termos sociais, seus interlocutores.

Sob influência da teoria de Grice (1982), Leech (1983) propõe que a orientação da comunicação pode se desenvolver a partir de outro princípio, o qual ele chamou de Polidez. Neste princípio, todas as ações do sujeito, ou self, segundo a sua proposta, se orientariam para um Outro. 
A polidez interessa-se pelo relacionamento entre dois participantes que nós podemos chamar de self e outro. Na conversação, normalmente, o self será indicado por $\mathrm{S}$ e outro tipicamente identificado por $\mathrm{H}$, mas falantes também demonstram polidez a terceiras partes que podem ou não ser apresentadas na situação de fala ${ }^{3}$ (LEECH, 1983, p. 131).

A partir desta definição, o autor (1983) sugere que os falantes devem orientar a polidez para o Outro, que pode ser seu interlocutor imediato, ou sujeitos que podem ou não estar presentes na situação de fala, mas que exercem influência sobre ela. Podemos compreender que o cerne da proposta de Leech (1983) é que a polidez, como numa espécie de atuação, serve para demonstrar para o Outro algum nível de importância que esta pessoa exerce sobre o falante.

Isso fica mais evidente quando Leech (1983) toma de empréstimo o termo "máximas" de Grice (1982) para propor que, para ser polido, o sujeito deve sempre maximizar os custos para si mesmo e minimizar os custos de seu interlocutor. Uma das consequências deste tipo de ação "altruísta" é que, agindo deste modo, o sujeito empreenderá uma boa imagem de si mesmo na interação, proporcionando-lhe aceitação social. Para o autor(1983), em muitos casos, os sujeitos preferem obedecer ao princípio de polidez, em vez do princípio de cooperação por ser mais relevantes, para esses sujeitos, estabelecer e manter laços sociais.

Baseando-se em Goffman (1967), cientista social que compara o indivíduo a um ator, cuja comunicação é um modo de encenação no qual os sujeitos "dão a sua face" a perceber, Brown e Levinson (1987) propuseram um modelo de estudo de polidez linguística, balizado pela proposição e pela sustentação da face na interação. Para isso, os linguistas (1987) sugeriram que os sujeitos na interação contariam com duas faces: uma positiva, caracterizada pelo desejo de compartilhar com o outro algo que o sujeito julgue relevante para aquela interação; e outra negativa, correspondente àquilo que o sujeito não deseja compartilhar, demonstrar, a fim de preservar a harmonia da interação.

Mais uma vez, o que está em jogo não é propriamente o conteúdo comunicacional do que é dito, mas a forma como é dito este conteúdo. Com base no conhecimento de mundo e na situação de fala, segundo Brown e Levinson (1987), os interlocutores são considerados sujeitos racionais capazes de elaborar enunciados polidos que visem a preservar as faces positiva e negativa, ou minimizar os efeitos dos atos ameaçadores de face, que, segundo eles, são atos de fala que podem provocar algum desconforto ou conflito na interação.

\footnotetext{
${ }^{3}$ Texto original: Politeness concerns a relationship between two participants whom we may call self and other. In conversation, self will normally be identified with s, and other will typically be identified with h; but speakers also show politeness to third parties, who may or not be present in the speech situation.
} 
Os autores (1987), na tentativa de avaliar a polidez de um modo mais positivista, lançaram mão de uma equação, que, segundo eles, ocorre na mente do enunciador no momento em que ele decide enunciar algo para seu interlocutor. A equação $\mathrm{Wx}=\mathrm{D}(\mathrm{S}, \mathrm{H})+\mathrm{P}(\mathrm{H}, \mathrm{S})+\mathrm{Rx}^{4}$ sugere que a polidez é medida a partir da soma do nível de intimidade entre o falante e seu interlocutor; do poder que um pode exercer sobre o outro; e do peso do ato ameaçador de face.

Deste modo, o sujeito, ao se encontrar com seu interagente, racionaliza, mensura, avalia esses três fatores, de tal modo que o possibilita acessar em sua memória a(s) estratégias de polidez que lhe assegura(m) a preservação de suas faces e as de seu interlocutor.

Segundo os autores (1987), a enunciação das estratégias de polidez linguística pode aparecer em dois momentos na interação: na realização do ato ameaçador de face e no reparo (derivado do primeiro, que visa a minimizar o seu peso, com a finalidade de minimizar o conflito na interação).

Com relação ao arcabouço de estratégias, pode-se dizer que elas foram identificadas a partir de um estudo sociolinguístico, no qual, ao estudarem três línguas, entre elas, o inglês, Brown e Levinson (1987) verificaram que os falantes, para serem polidos, fazem uso de quarenta (40) estratégias de polidez que podem ser enunciadas de modo direto ou indireto para seus coenunciadores.

Os autores (1987) sustentam que as estratégias de polidez positiva permitem que o locutor invista na relação com seu interlocutor, demonstrando cooperação, entendimento, simpatia e, ao mesmo tempo, promovendo uma negociação conversacional. Desse modo, realizando ou reparando um ato ameaçador de face, o locutor busca evidenciar a importância de manter o interlocutor presente/ativo na interação e, dependendo da estratégia, estabelecer com ele algum nível de intimidade.

Já as estratégias de polidez negativa sinalizam que o locutor procura evidenciar o distanciamento entre ele e seu alocutário, a fim desrespeitar a sua intimidade, o seu espaço. Observa-se também que ele também procura se distanciar do ato ameaçador de face, especialmente, se ele põe em risco o investimento na relação.

Entre as estratégias de polidez negativa, os autores (1987) sugerem que o falante deve categorizar um ato de ameaça a face como uma regra geral, para, a partir disso, podermos inferir que situações desconfortáveis recorrentes, por exemplo, podem ser acionadas na conversação como modo de justificar determinado comportamento linguístico do locutor.

\footnotetext{
${ }^{4}$ Polidez $=$ Distância $($ Falante; Ouvinte $)+$ Poder(Falante;Ouvinte $)+$ Peso do ato ameaçador de face.
} 
Além dessas estratégias, Brown e Levinson (1987) propõem um conjunto de 5 estratégias de polidez linguística. A estratégia Off-Record indica uma tendência menos altruísta por parte do falante, que, por sua vez, parece estar mais preocupado em salvar, manter ou preservar a própria face do que oferecer para seu interlocutor clareza com relação às suas intenções e ao conteúdo comunicado, o que, para Watts (2004) e Locher (2004), pode trazer questionamentos para o status de polidez, tendo em vista que o conceito prevê o cuidado com as faces de si e do outro.

Considerando que a polidez linguística se ocupa não somente das faces, mas do distanciamento do conflito interacional, julgamos que o uso das estratégias Off-Record podem funcionar para esta finalidade, tendo em vista não deixar claro o posicionamento de si a respeito de temas considerados como gatilhos para uma discussão conflituosa.

Com base no modelo de polidez linguística de Brown e Levinson (1987), Culpeper (1996) propõe que a impolidez linguística opera de modo similar ao destacado pelos autores já referenciados, sendo que estase realiza quando os locutores têm a intenção de atacar as faces positiva e negativa do seu interlocutor. Em outras palavras, Culpeper(1996) julga que, assim como os sujeitos constroem ao longo de sua vida um acervo de estratégias de polidez, eles também constroem um acervo de impolidez e podem, deliberadamente, atacar uns aos outros, com vistas a instaurar ou manter um conflito na interação.

Ao contrário de Brown e Levinson (1987),que dividiram suas estratégias de polidez em três categorias, Culpeper (1996) propôs que a impolidez pode se realizar em até cinco categorias, a saber: impolidez clara; impolidez positiva; impolidez negativa; sarcasmo; e polidez suspensa.

Culpeper (1996) propõe uma série de estratégias de impolidez positiva e negativa. As estratégias de impolidez positiva são realizadas com a intenção de atacar ou menosprezar a face positiva do interlocutor, ou seja, ao passo em que ele investe na sua imagem positiva, o falante empenha-se em desconstrui-la. Já as estratégias de impolidez negativa indicam que o locutor pretende evidenciar tudo aquilo que seu alocutário pretende evitar na interação.

Do modo como o autor (1996) apresentou seu modelo de análise, pode-se imaginara polidez e a impolidez em dois polos opostos, que não se confundem, não compartilham de espaços simbólicos. No entanto, nossa proposta aqui é apresentar exatamente o contrário: é demonstrar que é possível se pensar em uma análise baseada em uma escala, cujas estratégias podem redimensionar ou recategorizar algo considerado como claramente impolido em algo polido e vice versa.

Koike (2017) e Marlangeon (2017), ao estudarem a impolidez, já destacam a natureza escalar dos enunciados dentro das interações. Os autores se amparam em diferentes perspectivas para indicar como um enunciado pode se tornar polido ou impolido dependendo de suas influências 
contextuais e culturais. Contudo, nesses estudos, não há a exposição da recategorização como recurso de transformação do sentido, ou mesmo como uma estratégia de polidez ou impolidez.

Acreditamos que a língua, especialmente se tomada como forma de agir no mundo, deve ser analisada sob um viés relativo, menos engessado, o que permite uma análise mais flutuante das capacidades de posicionamento criativo dos sujeitos. Deste modo, propomos uma análise baseada na (im)polidez linguística, cujas categorias analíticas possam permitir uma melhor compreensão do comportamento verbal.

\section{2. (RE)CATEGORIZAÇÃ̃}

A concepção clássica de recategorização apresentada por Apothéloz e Reichler-Béguelin (1995) foi um marco importante para a percepção das estratégias de retomada de elementos textuais e da continuidade discursiva. No rastro dos conceitos desenvolvidos por esses dois autores, novos sentidos para o ato de recategorizar foram sendo construídos, à medida que se avançavam as considerações acerca da linguagem como realização social, e não mais apenas como um produto formal da existência.

Se pensarmos ao pé da letra, (re)categorizar seria categorizar novamente. Nesse sentido, conforme Zavam (2007) explica, categorizar é a habilidade cognitiva que possibilita ao homem dar sentido àquilo que experiencia e compartilha. Para Bruner (1974), apud Ciulla (2008, p. 23), “perceber é categorizar, conceitualizar é categorizar, aprender é formar categorias, tomar decisões é categorizar”. Então, com base em Zavam (2007) e Bruner (1974), apud Ciulla (2008), poderíamos, inicialmente, afirmar que toda decisão que tomamos para comunicar, seja ao falar ou ao escrever um texto, estamos agindo "categoricamente".

Assim, por exemplo, se tomarmos o processo criativo dos designers para pensar a categorização, veremos que, ao montar um layout, eles estão fazendo escolhas pautadas em um interesse e em um objetivo. Esse ato de escolher seria, então, o fenômeno de categorização acontecendo. Desse modo, a serviço de tal discurso vamos escolhendo e, conforme a concepção clássica de recategorização, vamos melhorando, até atingir o objetivo comunicativo.

Da mesma maneira, ao olharmos para as interações pessoais, veremos que, se quisermos preservar a face de nosso interlocutor, a estratégia discursiva adotada nos levaria a fazer escolhas polidas; do contrário, se quiséssemos expor o nosso interlocutor, as escolhas tenderiam ao campo da impolidez linguística. Apothéloz (2001) explica que os participantes ajustam suas ações no decorrer da enunciação, categorizando e recategorizando os objetos que emergem em tais interações. Como se pode ver, o projeto de dizer que temos é que baliza as escolhas que fazemos e funciona, ainda, 
como uma espécie de filtro por onde passam as informações que nos servem de referentes no mundo. Daí porque compreender que os processos de recategorização não se dão apenas no plano da materialização do discurso, mas, sobretudo, no plano sociocognitivo-discursivo, pois, como nos faz ver Cavalcante (2011, p. 119), “dentro dessa abordagem [...] os processos referenciais não precisam, necessariamente, estar associados à menção de expressões referenciais para serem introduzidos no universo de discurso criado a partir do texto".

Sob esse mesmo prisma, Jaguaribe (2007), ao reforçar o caráter social da comunicação, entende e defende que "o ato de recategorizar envolve um processo mental [...] mas envolve também uma dimensão social", uma vez que se efetiva com o fito de garantir a evolução da comunicação. Assim, baseados nessa lógica e amparados em uma concepção dinâmica de texto, defendemos, também, um status de recategorização que se orienta para a extra materialidade, inclusive, para a intenção de ser ou não polido.

Desse modo, compreendemos o processo de discretização do mundo nos discursos não só como ações de categorização, mas também de recategorização. Então, podemos produzir enunciados polidos ou impolidos a depender de nossa intenção e do grau de intimidade que temos com o interlocutor, do poder que temos em relação a ele, do contexto e da cultura. Nessa perspectiva, os referentes discursivos serão tomados e retomados conforme a intenção, e, dito isso, chegamos à seguinte conclusão: os sentidos são relativamente estáveis, e, por isso, não podemos, a grosso modo, afirmar que um enunciado isoladamente é ofensivo ou inofensivo, porque existem uma série de fatores que articulados podem recategorizar esse sentido.

Em outras palavras, entendemos que aquilo que não se encontra explícito na superfície textual - valores sociais, culturais, conhecimentos específicos e particulares -também sofrem e geram efeitos recategorizadores. Do mesmo modo, a depender da intenção, as enunciações dos interlocutores do ato de fala são recategorizados nas escolhas operadas durante a construção compartilhada dos sentidos.

Em Oliveira (2017), observamos a recategorização na construção de graffitis e constatamos que a atualização e a retomada de elementos não ocorriam somente na superfície do graffiti, estando para além dela. As histórias de vida, o cotidiano local, as referências pessoais, as ruas, os muros e as comunidades que recebiam essas intervenções urbanas forneciam elementos extra materiais que seriam/foram retomados e recategorizados, gerando novos efeitos de sentidos. Desse modo, o entorno, as ruas, as comunidades, as pessoas eram também recategorizadas, passando a ocupar um novo status no conceito dos pedestres e moradores dos endereços grafitados.

Assim, levados por essa observação e considerando a comunicação como uma rede de criação permanente, compreendemos que tal lógica de atualização pode, da mesma forma, mudar 
percepções, gerar condutas de polidez ou impolidez em uma situação dialógica do cotidiano, pois, uma vez que se possa atualizar um conceito, um termo ou outro elemento da arquitetura textual para construir ou reconstruir sentidos, o mesmo poderá ocorrer coma imagem das pessoas bem como coma realidade circundante e, ainda, com o contexto da comunicação face a face.

Culpeper (1996) afirmou que a impolidez pode se realizar em até cinco categorias: impolidez clara; impolidez positiva; impolidez negativa; sarcasmos; e polidez suspensa. Nesse sentido, o fenômeno da recategorização seria entendido como mais um recurso que pode ser utilizado para evidenciar um ponto de vista sobre o caráter ou sobre a personalidade do interlocutor que, por sua vez, poderia ser manifestado por meio da ironia ou do sarcasmo. Isto é, pode-se adotar um nome ou uma expressão para avaliar negativamente uma pessoa em função dos valores pessoais e culturais ligados a uma das partes envolvidas no ato de fala. Apothéloz e Reichler-Béguelin (1995, p. 247) nos dão a entender que "toda expressão referencial pode ainda ser usada para ajustar saberes disponíveis sobre o objeto de discurso. Ou seja, é sempre possível imprimir sobre a expressão encarregada de retomar o objeto de discurso algumas informações cuja razão para a utilização não seja referencial". Nesse caso, as razões podem ser as de expor ao ridículo, constranger, mas também preservar a face, promover respeito e valorizar o outro.

Seria, portanto, a (re)categorização o instrumento situado na interface entre a polidez e a impolidez linguística, dado que os efeitos dessa estratégia recaem sobre o papel social dos sujeitos, podendo gerar contentamento ou produzir constrangimento. Nesse sentido, os efeitos produzidos dependeriam das estratégias de polidez ou impolidez escolhidas para a ocasião.

Por essa razão, propomos para o presente artigo a análise do fenômeno de recategorização que se evidencia na transformação do sentido de um enunciado notadamente ofensivo para um de sentido não ofensivo.

\section{Metodologia}

As teorias metodológicas dão conta que pesquisas aplicadas são aquelas envolvidas em gerar conhecimentos a partir de uma aplicação prática. Dessa maneira, os resultados obtidos por meio de tal aplicação servem para constatação ou esclarecimento de premissas previamente traçadas. Aliadas a um método observacional em que o cientista, conforme esclarece Gil (2008), apud Prodanov e Freitas(2013, p. 37), “apenas observa algo que acontece ou já aconteceu”, a pesquisa aplicada pode ser um instrumento gerador de importantes avanços no campo conceitual de teorias. 
Assim, como nosso objetivo para este artigo é o de apresentar o fenômeno de recategorização agindo na passagem de uma estratégia de impolidez para a de uma polidez em uma ação específica de endomarketing, julgamos que a opção por pesquisa aplicada nos auxiliaria a observar o fenômeno da recategorização ocorrendo para além da materialidade e, ainda, mostraria ser possível estabelecermos um redimensionamento de pontos entre a polidez e a impolidez, desconstruindo a ideia de que elas podem ser tomadas apenas como pólos estanques e opostos.

Nesse sentido, adotamos ainda a pesquisa exploratória, por buscar "orientar a fixação dos objetivos e a formulação das hipóteses ou descobrir um novo tipo de enfoque para o assunto." (PRODANOV; FREITAS, 2013, p. 52); e a descritiva, como complemento dessa estratégia metodológica, uma vez que esta “observa, registra, analisa e ordena dados, sem manipulá-los, isto é, sem interferência do pesquisador” (PRODANOV; FREITAS, 2013, p. 52).

Assim, a exploração da temática foi feita por intermédio de uma pesquisa bibliográfica, que nos deu o aporte para tratar das teorias elencadas no presente estudo (LEECH, 1983; GOFFMAN, 1967;BROWN; LEVINSON, 1987; CULPEPER, 1996; APOTHÉLOZ; REICHLER BÉGUELIN, 1995; JAGUARIBE, 2007; OLIVEIRA, 2017) associada à análise de exemplos selecionados a partir do material gerado por uma campanha de publicidade interna da Coca-Cola alusiva ao dia do orgulho LGBT. A coleta, portanto, foi feita em sites institucionais e páginas particulares na internet cujo conteúdo estava disponível para recolha. Esses dados coletados nos permitiram a verificação da aplicabilidade de nossa hipótese e a constatação dela por meio dos resultados obtidos, que serão apresentados na seção seguinte.

Ainda tratando de nosso atual objetivo, adotamos o procedimento do estudo de caso, que representa a aplicação imediata de conhecimentos em uma realidade circunstancial, relevando o desenvolvimento de teorias (PRODANOV; FREITAS, 2013, p. 60). Como se percebe, é possível traçar uma relação entre esse procedimento e a pesquisa aplicada, uma vez que Boaventura (2004) afirma que nessa metodologia de observação se busca a aplicação prática de conhecimentos para a solução de problemas sociais.

Nesse sentido, nossas observações recaíram sobre a apropriação feita por uma empresa de refrigerantes de uma expressão idiomática ativadora de sentidos figurados (“essa coca é Fanta”), uma vez que entendemos que a marca pretendia recategorizar os sentidos tradicionalmente atribuídos, lançando mão de um dado extra-textual na construção material da expressão "essa coca é Fanta. E daí?" e, com isso, remodelando o status de impolidez tradicionalmente relacionado a essa expressão.

Como se pode ver, o percurso metodológico descrito aqui expôs as escolhas teóricas em articulação com as escolhas metodológicas, de modo a relacioná-las ao processo seguido por nós 
para a organização prática da pesquisa. No próximo item, nos dedicamos a apresentar a reflexão empreendida na observação dos dados coletados.

\section{A RECATEgoriZAÇÃo NA INTERFACE DA IMPOLIDEZ E POLIDEZ: PROPOSIÇÃo E ANÁLISE}

\subsection{A proposição da estratégia de recategorização no plano do dizer}

Figura 1 - Campanha da Coca-Cola

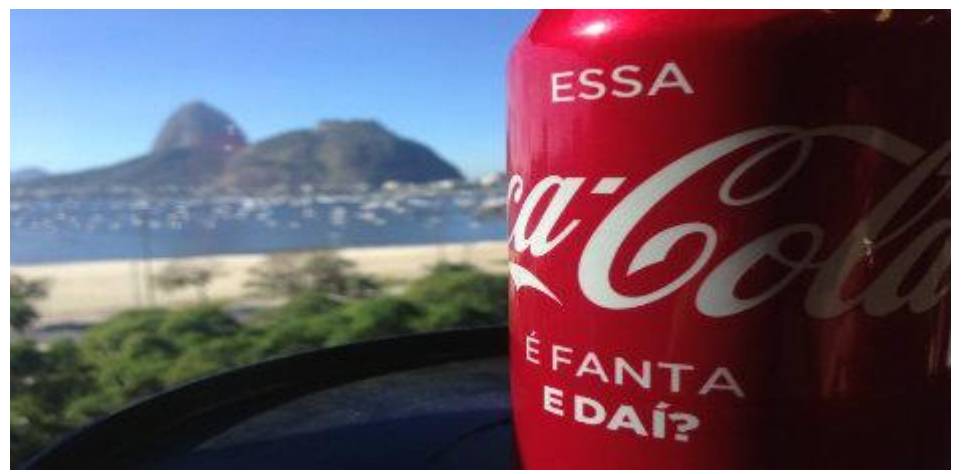

Fonte:

http://jconlineimagem.ne10.uol.com.br/imagem/noticia/2017/06/28/normal/d05959d83127b89ecce55b349600cb30.jpg

Com base na estratégia proposta por Brown e Levinson (1987, p. 206): categorize um ato de ameaça a face como regra geral, pela qual o locutor busca minimizar o peso do ato ameaçador de face justificando-o como uma regra, ou mesmo costume particular de um grupo ou prática deste grupo, propomos que um movimento inverso pode ocorrer, podendo assumir um estatuto de impolidez ou polidez, conforme ilustra a figura 1.

Na figura 1, a lata do refrigerante contém a seguinte frase: “essa coca é Fanta. E daí?”. Considera-se culturalmente que a expressão "essa coca é Fanta" é ofensiva, homofóbica. Desse modo, se A e B reconhecem X como um ato ameaçador de face, porque este se configura como uma ofensa, mesmo que velada, e/ou categorizada como uma regra para se referir a determinado grupo social, se A se preocupa com as faces de B, ele pode: I) não proferir a sentença; II) proferir a sentença sem reparo; III) proferir a sentença com reparo. Certamente, a opção mais polida seria que A não proferisse a sentença, a fim de evitar toda e qualquer associação da expressão ofensiva a si mesmo e ao seu interlocutor. Se porventura A proferisse a sentença sem reparo, ele indicaria para seu interlocutor não se importar com o fato de ele se sentir ofendido com o que foi dito, mostrando, talvez, que A talvez possa querer ser, deliberadamente, ofensivo ou reconhecido por isto.

De outro modo, se A proferisse a sentença, mas nela realizasse um reparo, de modo que este sinalizasse para B que A se preocupou em minimizar o peso do ato ameaçador de face ou evitar 
algum tipo de associação com ele, A estaria, ainda assim, sendo polido. Aqui jaz as observações de Brown e Levinson (1987) a respeito das interações polidas realizadas face a face.

Nos exemplos apresentados por Brown e Levinson (1987) em relação às estratégias de polidez positiva e negativa, há uma preocupação de que o ato ameaçador de face seja evitado, minimizado, dissociado. No caso da nossa proposta, acreditamos que a polidez também possa ser empreendida a partir da manutenção do peso do ato ameaçador de face, com a retomada da expressão pejorativa "essa coca é Fanta", seguida da tentativa de suavização desse peso com a expressão "e daí". Assim, por meio da recategorização material - a inclusão do "e daí" -, a empresa atenua o ato ameaçador de face e propõe a mudança de sentido, de modo que, no lugar de promover ofensa, poderia significar liberdade de expressão quanto à sexualidade.

Diante disso, para tornar mais clara a nossa proposta, apresentamos a figura 2, que demonstra onde a recategorização pode estar inserida no quadro teórico/metodológico, de modo a contemplar a natureza fluida do sentido e a transformação da (im)polidez em polidez.

Nosso estudo propõe que A pode agir com polidez em relação a B, mesmo se A optasse por não evitar a associação com o ato ameaçador de face ou por minimizar o seu peso. Assim, B ainda reconheceria o mesmo peso do ato ameaçador de face, mas, em vez de se sentir ofendido, poderia, no campo da interpretação, atuar junto com A no processo de recategorização do ato ameaçador de face.

Vejamos novamente a figura 1 , que apresenta a campanha de marketing interno promovida pela empresa Coca-Cola no dia de comemoração do orgulho LGBT na cidade do Rio de Janeiro. Para a nossa análise, consideramos a empresa Coca-Cola como enunciador da mensagem (A) e o público-alvo da campanha como os funcionários da empresa no Rio de Janeiro como coenunciadores imediatos, e o grupo LGBT e outros como co-enunciadores indiretos da mensagem (B).

Figura 2 - Proposta de modelo de Polidez Linguística com a inserção da estratégia de reparo recategorizador 


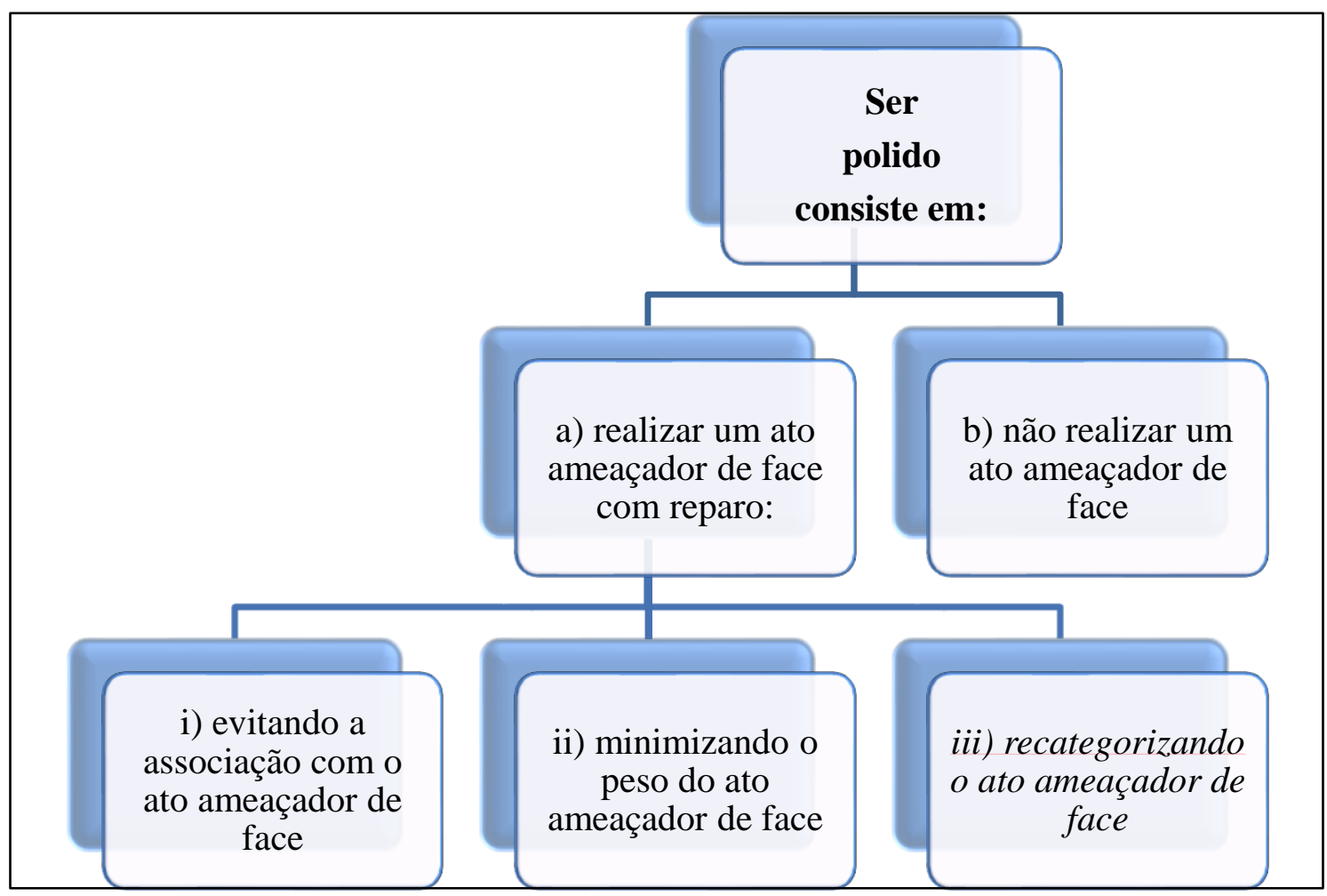

Fonte: elaboração própria

No caso desta campanha, afirmamos que o movimento de recategorização acontece em duas instâncias: na dimensão material - expresso pelo linguístico e pelo imagético - e ainda na dimensão social - percebido no campo extra material. A nosso ver, a empresa foi polida quando usou da estratégia: recategorize um ato ameaçador de face.

Para realizar um empreendimento tão arriscado, no dia 28 de junho de 2017, dia em que se comemora a luta em prol do orgulho LGBT, a empresa distribuiu várias latinhas de Fanta Laranja nas geladeiras do prédio onde funciona a sede da empresa no Rio de Janeiro. As latinhas de Fanta, por sua vez, estavam com uma embalagem nova, embalagens de Coca-Cola contendo a expressão “Essa Coca-Cola é Fanta. E daí?”.

Ao trocar a embalagem do refrigerante de fruta pela embalagem de outro refrigerante, a empresa efetuou o primeiro tipo de recategorização baseado na literalidade da expressão idiomática (recategorização na dimensão material), o que reforça o conteúdo ofensivo da mensagem. No entanto, o teor ofensivo passou também, a nosso ver, por um movimento recategorizador sociocognitivo (recategorização na dimensão extra material). No que se refere ao aspecto material dessa percepção, é a instância linguística, com a inserção do termo "Cola" no meio do enunciado ofensivo, que dispara a recategorização, progredindo para a dimensão extra material com a adição da pergunta "E daí?". 
Como é de conhecimento geral, "Essa coca é Fanta" consiste em expressão idiomática pejorativa e metafórica que se apropria de elementos da indústria cultural para associar as pessoas às condições LGBT, sugerindo que, por trás daquela "embalagem", há um sujeito que se expressa como seu gênero oposto, ou mantém relações sexuais com o mesmo gênero. À priori, por ser uma metáfora, essa expressão poderia se encaixar como uma realização polida, mas, por estar cristalizada em nossa língua e se ligar a um sentido também cristalizado, sua capacidade metafórica apenas reforça a nominalização, estratégia de impolidez observada por Culpeper (1996).

Deste modo, os falantes de português brasileiro reconhecem a expressão supracitada como ofensiva, e, em algum nível, tabu, pela sua associação direta com o grupo LGBT. Temos aí uma sentença que, dependendo da forma com que é realizada, pode agregar não apenas uma, mas várias estratégias de impolidez ao mesmo tempo.

A inserção da palavra "Cola" depois de "Coca" mostra-nos que o enunciador tem consciência do uso e associa, explicitamente, a si mesmo o ato ofensivo, uma vez que na expressão original ocultava-se o restante da marca de refrigerante. Tal posicionamento da empresa demonstra que ela se preocupa com a sua imagem e assume a responsabilidade pelo que está sendo veiculado. Trata-se de uma ação corajosa, tendo em vista que a expressão idiomática é categoricamente ofensiva.

Ainda na superfície do texto, a pergunta "E daí?", por sua vez, interpela o interlocutor e o convida a refletir sobre a (re)categorização ofensiva do sujeito como membro LGBT, e, desse modo, aciona e retoma o seu referente. Nesse movimento, a marca Coca-Cola, agora explícita na expressão ofensiva, leva seus consumidores a refletirem sobre a discriminação e a ridicularização dos LGBTs. Como podemos observar, ao incluir-se declaradamente na embalagem, não há dissociação ou busca pela redução do peso do ato ameaçador de face, mas uma tentativa de recategorização do ato ameaçador de face realizado pela marca, que, em função das palavras presentes no verso da embalagem, se pretende projetar como transgressora, vanguardista, conforme ilustra a figura 3.

Neste cenário, podemos compreender que a empresa Coca-Cola buscou ser polida, na medida em que proferiu um ato ameaçador com reparo distinto do que é descrito pela literatura tradicional em estudos de polidez linguística, uma vez que o ato foi minimizado por meio do recurso da recategorização que, por seu turno, ocorreu com base na retomada criativa e responsiva da empresa, o que gerou a sugestão de uma construção de sentido diversa do que foi documentado por Brown e Levinson (1987) e, consequentemente, trouxe para a marca uma repercussão bastante positiva em sites de redes sociais. 


\subsection{A recategorização no plano do ser LGBT e a repercussão da ação de marketing na internet}

Sob influência de Hegel, Lacan, Austin, Althusser, entre outros, Judith Butler (1990) entende que o sujeito é uma entidade formada a partir de uma construção identitária menos livre do que pregavam os movimentos de libertação gay das décadas de 1950 e 1960. Segundo a autora, essa construção é determinada a partir da relação de conflitos de poder, cuja estrutura mais forte é aquela que opacifica a mais frágil, e, desse modo, o sujeito assujeitado produto desta luta, acaba atuando de modo a performar o discurso dominante.

Apesar de entender de modo um tanto pessimista e pouco autônomo o papel do sujeito, Butler (1990) ressalta que as categorias, formas com as quais lemos e construímos a nossa ideia de realidade, apesar de serem oriundas de uma perspectiva binária e ligada ao biológico, não estão estanques e, embora pareçam cristalizadas, podem estar em estado de conflito com outras categorias, o que repercute na recategorização, provocando novos processos de naturalização.

Ao tentar compreender mais sobre a genealogia do sujeito, Butler $(1990 ; 1993)$ encontra no processo de recategorização de gênero e de sexo um instrumento importante não somente na construção, como na desconstrução e na subversão da identidade. Essa constatação demonstra a capacidade heterogênea e plural que consegue abarcar todos àqueles que podem ser alocados como LGBTs numa ideologia Queer.

O movimento Queer, ao subverter a lógica que separa as fronteiras sexuais em dois grupos apenas, demonstra uma apropriação do lugar do sujeito, como um ser construído, influenciado pelo seu próprio tempo e situado para além das normas que regulam a sua atuação. Sob o escopo dessa teoria, esse sujeito é plural, múltiplo e fragmentado, questionador de verdades permanentes, crente em verdades provisórias, é um sujeito pós-moderno, integrado em todas as camadas, fluído, plástico.

Nesse contexto de verdades provisórias e de recategorizações do ser necessárias para a sobrevivência nos tempos pós-modernos, entendemos que a publicidade atua como instrumento que permite conhecer, compreender, acompanhar e regular ${ }^{5}$ os discursos das categorias. Desse modo, excluir uma categoria que luta para ser "reconhecida" sem o rótulo de constrangimento que lhe tem sido imposto desde sempre, e que, conforme o tempo passa, ganha mais membros, é ignorar a força de um público-consumidor de símbolos e marcas que não são apenas de um produto, mas principalmente marcas de grupos. A força de identificação desses grupos, a nosso ver, amparados por questões midiáticas, como as que se instauraram por meio dessa campanha de endomarketing,

\footnotetext{
${ }^{5}$ Baseada nos estudos de Althusser, Butler (1990) entende que a indústria cultural pode não apenas divulgar, como também condicionar e modelar os discursos.
} 
auxiliam os sujeitos a se representar e a representar tais grupos e ainda pode "ajudá-los" a performar nas mais diferentes camadas sociais.

Julgamos que a ação de marketing interno que decidimos analisar ilustra essa iniciativa. Ainda que,em princípio, tenha sido pensada para atingir somente ao público interno da empresa e que, apenas por meio das redes sociais, “escapou” para o público geral, não podemos deixar de notar a força representativa e recategorizante dessa estratégia que, por meio das relações sociais existentes, possibilitou a operação da recategorização no nível do real intersubjetivo.

A repercussão pública da ação de endomarketing da Coca-Cola pôde ser percebida a partir das inúmeras postagens e (re)postagens feitas com as imagens das latinhas.O buscador Google, por exemplo, apresentou- referente a essa campanha -um total de quatrocentos e setenta mil resultados, dos quais se destacam as imagens da latinha comemorativa e as notícias relacionadas à ação de marketing.Depois das postagens iniciais, a apropriação pelo público se deu instantaneamente, e, até a data de finalização deste artigo, o site de rede social Instagram já contava com mais de mil menções à expressão idiomática, sendo as mais recentes referentes à campanha de marketing interno da Coca-Cola.

Figura 3 - Exemplo de postagem da latinha no Instagram

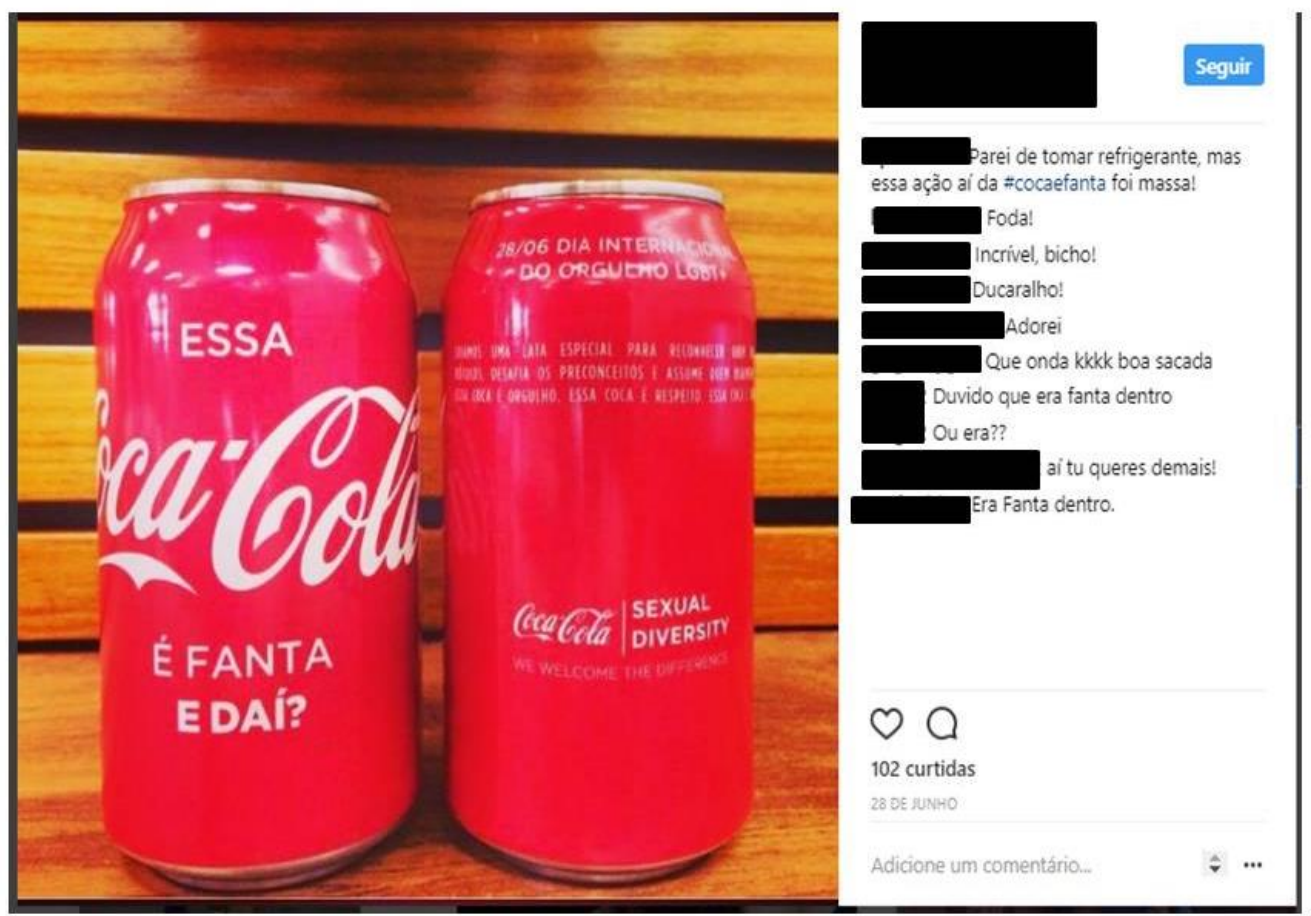

Fonte: https://www.instagram.com/p/BV5LL4elsL5/?tagged=cocaefanta 
A partir das observações de tais registros publicados nas redes sociais, pudemos perceber que as postagens da foto da latinha comemorativa, que apresentavam as hashtags \#essacocaefanta \#essacocaéfanta e \#essacocaefantaedaí, geraram engajamento positivo entre as pessoas, que elogiaram a estratégia de marketing da empresa, como podemos constatar na figura 3.

Apesar de não ter sido o foco dos estudos tradicionais de polidez linguística, ao analisar situações de uso diversas das interações face a face entre falante e ouvinte, observamos aqui que a interação institucional da empresa com seus consumidores apresenta polidez, tendo em vista que a empresa, nesta campanha, se preocupou com as faces de seu público-alvo ao propor uma campanha como esta. Este, por sua vez, retorna à empresa sentimentos desimpatia, de solidariedade e, no caso de redes sociais, de visibilidade.

Por fim, reiteramos ainda que tal campanha pode ser vista também como processo de recategorização ocorrendo no real intersubjetivo sobre a ideia de ser e pertencer, pois há a possibilidade de essa atitude promover uma minimização dos impactos históricos da discriminação contra os homossexuais, que prometem dar visibilidade à luta simbólica deste grupo em ocupar espaço discursivo legítimo, mas publicizado por esta campanha e por outras muitas.

\section{CONSIDERAÇÕES FINAIS}

Esta pesquisa teve como objetivo geral compreender o processo de recategorização sob a perspectiva de uma interface entre a polidez e a impolidez linguística. Para isso, escolhemos analisar uma ação de comunicação interna desenvolvida pela empresa Coca-cola em comemoração ao dia do orgulho LGBT. Nossa proposta de estudo recai sobre a desconstrução da estratégia de impolidez percebida por meio do uso da expressão "essa coca é Fanta" e sobre a reconstrução dessa mesma estratégia, a partir do enunciado “essa Coca-Cola é Fanta. E daí?”.

A experiência de analisar uma campanha de marketing com tamanha engenhosidade nos levou a refletir sobre a proposição de limites entre os estatutos já consagrados da literatura sobre polidez e impolidez linguística. Acreditamos que os corpora adotados pelos linguistas, os períodos e as situações, cujos dados linguísticos foram coletados, devem ter interferido significativamente para que Brown e Levinson (1987) e Culpeper (1996) tenham observado tais estratégias para a manifestação de polidez e impolidez.

Pretendemos, com esse artigo, lançar mão do conhecimento desses autores para compreender o processo de recategorização como instrumento de interface entre a polidez e impolidez linguística, a partir da análise da ação de comunicação interna promovida pela empresa Coca-Cola para a comemoração do dia Internacional do Orgulho LGBT no ano de 2017. Entretanto, 
para isso, foi preciso fazer considerações e alguns ajustes, tendo em vista a natureza do caso analisado.

Com isso, cremos que nosso trabalho apresentou suas primeiras contribuições: demonstrar que é possível fazer uma análise de (im)polidez linguística em interações assíncronas e nos termos da relação instituição e público-alvo, sendo cada um deles mantenedores de faces positiva e negativa. A partir disso, foi possível propor um ajuste ao modelo clássico de polidez de Brown e Levinson (1987) demonstrando que os enunciadores podem ser polidos não apenas minimizando o peso ou evitando associação com o ato ameaçador de face, mas recategorizando o seu conteúdo ofensivo. Tal ajuste implicou uma correlação direta com as estratégias de impolidez de Culpeper (1996), levando-nos a concluir que estudar polidez sem a impolidez, ou vice-versa, não é um caminho profícuo, pelo contrário.

A partir da escolha desta campanha, foi possível observar a importância dos componentes não linguísticos como fatores importantes do acionamento e da ratificação do conteúdo proposicional, que, neste caso, transgrediu o tom ofensivo, recategorizando-o em polido, e ressaltando, assim, a capacidade criativa e polissêmica que a linguagem tem ao alcançar as mentes habilidosas de seus locutores.

Nosso trabalho não pretende desmerecer os escritos tradicionais sobre polidez e impolidez, tampouco lhes tecer críticas negativas. Intentamos colaborar para o desenvolvimento de uma teoria, a qual contempla aspectos importantes para a compreensão do fenômeno que opera mais nas nossas decisões do cotidiano do que propriamente a simples necessidade de comunicar algo, tendo em vista que a nossa necessidade de socialização assume um papel crucial sobre as nossas escolhas linguísticas e não linguísticas.

\section{REFERENCIAS}

APOTHÉLOZ, D.. Référer sans expression. Référencielle: gestion de laréférence et opérations de reformulation dans des séquences métalinuistiques produites dans une tâche de rédaction conversationelle. In: ENIKÖ, N. (ed.). Pragmatics in 2000: selected papers from the 7th International Pragmatics Conference, v. 2. Antwerp: International Pragmatics Association, 2001. APOTHÉLOZ, D.; REICHLER-BÉGUELIN, M.J.. Construction de la reference et strategies de designation. In: BERRENDONNER, A.; REICHLER-BEGUELIN, M.J. (Eds.). Du syntagme nominal auxobjets-de-discours: SN complexes,nominalizations, anaphores. Suisse: Institut de Linguistic de l’Université de Neuchâtel, 1995.

BOAVENTURA, E. M. Metodologia da Pesquisa: monografia, dissertação e tese. São Paulo: Atlas, 2004. 
BROWN, P.; LEVINSON, S. Politeness: some universals in language usage. Cambridge: Cambridge University Press, 1987.

BUTLER, J. Gender trouble: Feminism and the subversion of identity. New York: Routledge, 1990.

BUTLER, J.Bodies that matter:on the discursive limits of sex. New York: Routledge, 1993.

CAVALCANTE, M. M. O processo Cognitivo-discursivo da Referência. In: CAVALCANTE, M. M. Referenciação: sobre coisas ditas e não ditas. Fortaleza: UFC, 2011.

CIULLA, A. Os processos de referência e suas funções discursivas:o universo literário dos contos. 2008. 201 f. Tese (Doutorado em Linguística) - Programa de Pós-graduação em Linguística, Universidade Federal do Ceará, Fortaleza, 2008.

CULPEPER, J. Towards na anatomy of impoliteness.JournalofPragmaticsv. 25, p. 349-367, 1996. Disponível em: http://dx.doi.org/10.1016/0378-2166(95)00014-3. Acesso em: 02 ago. 2017.

GRICE, H. P. Lógica e conversação. In: DASCAL, M. (org.). Pragmática: problemas, críticas, perspectivas da lingüística. Campinas: Edição do autor, 1982.

GOFFMAN, E. Interaction ritual: essays on face-to-face behavior. Garden City: Anchor Doubleday, 1967.

JAGUARIBE, V. M. F. Os caprichos e as condescendências do discurso literário. In: CAVALCANTE, M. M.; COSTA, M.H.A.; JAGUARIBE, V.F.; CUSTÓDIO FILHO, V. (org.). Texto discurso sob múltiplos olhares: referenciação e outros domínios discursivos. v. 2. Rio de Janeiro: Lucerna, 2007.

KOIKE, D.A. Os frames culturais na fala: expectativas para a (des)cortesia. In: CABRAL, A. L. T.; SEARA, I. R.; GUARANHA, M.F. (org.). Descortesia e cortesia: expressão de culturas. São Paulo: Cortez, 2017.

LAKOFF, R. The logic of politeness; or, minding your P's and Q's. In: CORUM, C.; SMITHSTARK, T. C.; WEISER, A. (ed.). Papers from the Ninth Regional Meeting of the Chicago Linguistics Society. Chicago: University of Chicago Press, p. 292-305, 1973.

LEECH, G. M. Principles of Pragmatics. London: Longman, 1983.

LOCHER, M.A. Power and politeness in action: Disagreements in oral Communication. Language, Power and Social Process. Berlin and New York: Mouton de Gruyter, 2004.

MARLANGEON, S. K. Contribuições para o estudo da descortesia verbal. In: CABRAL, A. L. T.; SEARA, I. R.; GUARANHA, M. F. (org.). Descortesia e cortesia: expressão de culturas. São Paulo: Cortez, 2017.

OLIVEIRA, F. P. L. Recategorização para além dos muros: a produção (inter)subjetiva de objetos de discurso no universo dos graffitis e a recriação da realidade. 2017. $284 \mathrm{f}$. Tese (Doutorado em Linguística Aplicada) Centro de Humanidades, Universidade Estadual do Ceará, Fortaleza, 2017.

PRODANOV, C. C.; FREITAS, E. C. Metodologia do trabalho científico: Métodos e Técnicas da Pesquisa e do Trabalho Acadêmico. 2. ed. Novo Hamburgo: Feevale, 2013. Disponível em: www.feevale.br/editora. Acesso em: 16 ago. 2017.

WATTS, J. R. Politeness: key topics in sociolinguistics. Cambridge: Cambridge Press, 2004.

ZAVAM, Aurea S. São axiológicas as anáforas encapsuladoras? In: CAVALCANTE, Mônica Magalhães et al. (org.). Texto e discurso sob múltiplos olhares: referenciação e outros domínios. Rio de Janeiro: Lucerna, 2007, v. 2, p. 123-143. 